\title{
Revista Brasileira de Enfermagem REBEn \\ Processos coletivos de produção de conhecimento em saúde: um olhar sobre o exercício de enfermagem no hospital
}

Colective process of knowledge production in health: an overview in hospital nursing practice

Proceso colectivo de producción de conocimiento en salud: una visión sobre el ejercicio de enfermería en el hospital

\section{Dagmar Elisabeth Estermann Meyer}

Enfermeira. Doutora em Educação. Professora Adjunto na Faculdade de Educação da Universidade Federal do Rio Grande do Sul. Pesquisadora do Grupo de Estudos de Educação e Relações de Gênero e bolsista de produtividade em pesquisa do CNPq.
Submissão: 07/04/2005

Aprovação: 07/12/2005

\section{RESUMO}

O artigo apresenta reflexões que decorrem de minha participação em uma mesa redonda em que se discutiu a temática Processos coletivos de produção de conhecimento em saúde. Com base em autores como Michel Foucault e Norbert Elias, dentre outros, procuro discutir e problematizar algumas dimensões do processo de produção de um conhecimento particular (o conhecimento científico), em um espaço singular (o hospital), considerando a posição de um saber-fazer específico (o de enfermagem) no contexto de uma prática profissional pontual (o registro ou as anotações de enfermagem) que têm como foco direto de seu trabalho a doença e o corpo doente. Para isso, estruturo o texto em torno de três perguntas inter-relacionadas e inter-dependentes: que saberes conformam e informam o fazer de enfermagem hospitalar? Que saberes o fazer de enfermagem, traduzido nos registros, reforça, legitima e retro-alimenta? Como isso se dá e com que efeitos, para quem? Descritores: Conhecimento; Cuidados de enfermagem; Serviço hospitalar de enfermagem; Registros de enfermagem.

\section{ABSTRACT}

The article presents some reflections based on the authors' participation in a workshop when the subject: colective processes of knowledge production in health was discussed. Based on other authors' ideas such as Michel Focault and Norbert Elias, the author's discussion concerns some dimensions over that process in a particular knowledge considering the hospital setting and also the position of specific nursing know-how in the context of professional practice (nursing records), with central focus in the work, the disease, and the sick body. In that direction the text is structured around three inter-related/dependent central questions: which knowledge configure nursing know how in hospital context? Which registered knowledge reinforce, legitimate and feed-back the nursing know how? How do this process accur, what and for who are those effects?

Descriptors: Knowledge; Nursing care; Nursing service, hospital; Nursing records.

\section{RESUMEN}

Este artículo presenta algunas reflexiones basadas en la participación de la autora en el workshop cuyo tema central discutió la producción del conocimiento colectivo en salud. Teniendo como basis las ideas de Michel Focault y Norbert Elias la autora discute sus preocupaciones con la dimensión sobre este proceso en un conocimiento particular al considerar el contexto hospitalario y tanbién la posición especifica del saber-hacer de la enfermería en el contexto de la práctica profesional (registros de enfermería), con foco central en el trabajo, la enfermedad y el cuerpo enfermo. En esta dirección el texto es estructurado por tres cuestiones interrelacionadas y inter-dependientes: cual conocimiento configura el saber-hacer de enfermería en el contexto hospitalario? Cual conocimiento registrado refuerza, legitima y regenera el saber-hacer de enfermería? Como este proceso ucurre, cual y para quien son los efectos?

Descriptores: Conocimiento; Atención de enfemrería; Registros de enfermería.

Meyer DEE. Processos coletivos de produção de conhecimentoem saúde: um olhar sobre o exercício de enfermagem no hospital. Rev Bras Enferm 2006 jan-fev; 59(1): 95-9.

\section{A DE-LIMITAÇÃO DE UM PERCURSO ARGUMENTATIVO}

As reflexões que apresento, aqui, sob a forma de artigo, decorrem de minha participação em uma mesa redonda que previa a discussão da temática Processos coletivos de produção de conhecimento em saúdea . A abordagem com que retomo esse amplo e complexo tema, neste texto, reproduz, então, a forma específica e pontual com a qual procurei responder ao teor do convite que justificava minha presença naquela mesa: discutir e levantar questões, do ponto de vista das relações poder-saber, acerca de algumas dimensões do processo de produção de um conhecimento particular

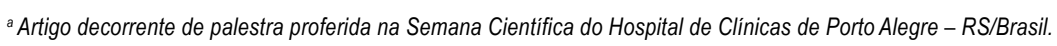


(o conhecimento científico), em um espaço singular (o hospital), considerando a posição de um saber-fazer específico (o de enfermagem) no contexto das práticas de saúde que têm como foco direto de seu trabalho a doença e o corpo doente.

E o que estou chamando de conhecimento científico neste contexto? De modo geral, nos referimos a uma série de características para diferenciar o conhecimento, qualificado como científico, de outros tipos de conhecimentos: ele seria um conhecimento crítico, fundamentado e que visa produzir interpretações de realidade; ele visa permitir um certo grau de generalização ou, dito de outro modo, pretende produzir um certo consenso sobre algo; ele é intencional porque constitui determinados objetos e pretende fornecer subsídios para compreendêlos ou produzir instrumentos de intervenção sobre eles; é um conhecimento sistematizado e que obedece às regras de um determinado campo e, por fim, ele é também um conhecimento que se pretende verdadeiro, para além do tempo e espaço de sua produção.

Aparece, aqui, então, uma primeira relação para a qual quero chamar atenção, que é a relação entre conhecimento científico e verdade. Que verdade é essa que a ciência pretende estar produzindo? Para que serve esse conhecimento que se orienta pela verdade? Como se constrói e funciona esse consenso tão poderoso que nos faz acreditar - como cientistas e intelectuais - que estamos posicionados em um lugar privilegiado de acesso a, e de reconhecimento da, verdade? Foucault ${ }^{(1)}$ enfatiza que a verdade não existe fora do poder ou sem poder. Isso é a mesma coisa que dizer que a verdade é legitimada como verdade no âmbito de determinados processos de validação do conhecimento que envolvem condições históricas, culturais, econômicas e políticas, matrizes disciplinares, conjunto de regras metodológicas, conceitos que precisamos admitir para falar de determinados objetos e é este conjunto de elementos que permite definir o que é que conta como verdade, em um determinado tempo e contexto. Com isso o autor quer dizer que a verdade e, portanto, os conhecimentos que a sustentam, são "deste mundo"(1). Nesse sentido, ele enfatiza que cada sociedade tem seu regime de verdade, isto é,

(...) os tipos de discursos que acolhe e que faz funcionar como verdadeiros, os mecanismos e as instâncias que permitem distinguir enunciados falsos de verdadeiros, a maneira como se sancionam uns e outros; as técnicas e os procedimentos que são valorizados para a obtenção disso que funciona como verdade, o estatuto daqueles que tem o encargo e a autoridade de dizer o que funciona como verdadeiro(1)

Isso, de certa forma, implica considerar duas coisas: a primeira é que, como todos os processos e relações deste mundo, o processo de produção de conhecimento envolve relações de poder; a segunda é que a instituição e operacionalização desses regimes de verdade centrados no discurso científico demandam a constituição concomitante de comunidades científicas no interior das quais se delimitam as condições de validação desses conhecimentos. De uma forma muito provocativa, Costa ${ }^{(2)}$ sintetiza isso dizendo que os conhecimentos científicos funcionam como crenças compartilhadas por determinados grupos, e que os campos de estudo e as comunidades que os integram e compõem podem ser entendidos como territórios e agentes de validação dessas crenças. O que poderia nos levar também a perguntar: quais crenças (ou discursos científicos) compartilhamos, como elas se constituíram e como fazem funcionar o regime de verdade que sustenta o saber-fazer na área da saúde, hoje?

Tendo em vista o que vim enfatizando, até aqui, é possível fazer mais uma pergunta: seria possivel pensar a produção de um conhecimento científico com essas características 'fora' ou desvinculada de determinados tipos de coletivos? Seria possivel pensar em conhecimentos produzidos por indivíduos, no sentido estrito do termo? Eu assumiria que não.

Assumindo então essa posição de que o processo de produzir conhecimento científico envolve sempre determinados coletivos, eu pretendo, então, na próxima seção, qualificar um pouco a noção de coletivo com que vou trabalhar aqui, considerando o processo de constituição das sociedades ocidentais modernas, nas quais o hospital vai-se estabelecer como a instituição referência de organização e intervenção no processo saúde-doença.

\section{O HOSPITAL COMO COLETIVO QUE PRODUZ E TRANSFORMA RELAÇÕES ENTRE SABER E PODER}

Quando descreve e analisa os processos de regulação e controle que atravessam e modulam a produção daquilo que chamamos de "civilização" das sociedades ocidentais, Elias ${ }^{(3)}$ desenvolve, em uma longa citação, um argumento que permite delinear a noção de coletivo que me interessa destacar:

Dos períodos mais remotos até os nossos dias, as funções sociais, sob pressão de diversos tipos de competição, tornaram-se cada vez mais diferenciadas. Quanto mais diferenciadas elas se tornavam, mais crescia o número de funções e, assim, de pessoas das quais o indivíduo constantemente dependia em todas as suas ações, desde as simples e comuns até as complexas e raras. À medida que mais pessoas sintonizavam sua conduta com a de outras, a teia de ações teria que se organizar de forma sempre mais rigorosa e precisa, afim de que cada ação individual desempenhasse uma função social. 0 individuo era compelido a regular sua conduta de maneira mais diferenciada, uniforme e estável (...) a direção dessa transformação da conduta, sob a forma de uma regulação crescentemente diferenciada era determinada pela direção do processo de diferenciação social, pela progressiva divisão de funções e pelo crescimento de cadeias de interdependência nas quais, direta ou indiretamente, (...) cada ação do indivíduo precisava ser integrada $(. . .)^{(3)}$.

É importante dar-se conta, em primeiro lugar, que é a esse processo de transformação e regulação da conduta, indispensável para 0 funcionamento dessas cadeias de interdependência, que o autor chama de civilizador. O termo, da forma como é usado por ele, pretende descrever uma forma de organização e funcionamento social que caracteriza o que ele chama de sociedades complexas e, nesse sentido, não carrega, em si, os sentidos de valoração com os quais ele é, comumente, usado para hierarquizar sociedades, culturas, grupos e indivíduos numa escala que opõe civilização a primitivismo para justificar o acesso diferenciado a bens e serviços que configuram relações sociais injustas e desiguais. Em segundo lugar, é possivel pensar que um coletivo sempre implica relações de interdependência, divisão de funções e estruturação interna de cada uma dessas funções, mesmo que elas sejam de natureza e de graus diversos. 0 que me leva à instituição hospitalar, pensada como coletivo e como um lócus onde opera uma extensa e complexa rede de saberes e de funções interdependentes e internamente estruturadas.

Como podemos situar a instituição hospitalar nesse contexto de civilização das sociedades ocidentais modernas? Foucault ${ }^{(4)}$ refere que, até meados do século XVIII, o hospital se configurava como um lugar de internamento que reunia indivíduos re-conhecidos e nomeados como doentes, loucos, criminosos, devassos e prostitutas e funcionava como uma espécie de instrumento de exclusão, assistência e transformação espiritual na qual a função médico-terapêutica pouco aparecia. Refere também que, dentre as condições que possibilitaram a "medicalização" do hospital e a "hospitalização" da medicina, estava a necessidade de "purificar a instituição de seus efeitos nocivos e da desordem que ele acarretava [...]; as doenças que ele podia suscitar nas pessoas internadas e espalhar na cidade em que estava situado, como também a desordem econômico-social de que ele era foco perpétuo"(4). Segundo o autor, dois movimentos concomitantes e inter-relacionados vão possibilitar a transformação dos hospitais em instituições médico - terapêuticas: a 
introdução de mecanismos de disciplinamento (do espaço, das relações e das formas de organização) da instituição que foram demandadas por questões econômicas; o preço atribuído ao indivíduo e à vida humana, bem como a necessidade de evitar epidemias e sua propagação; e a transformação do saber e da prática médicas. Desse encontro do hospital com a medicina é preciso destacar, considerandose o tema do artigo, que uma das estratégias centrais desse processo de medicalização do hospital foi a organização de um sistema de registro permanente e exaustivo do que ali acontece: identificação dos doentes; acúmulo e transmissão de informações (que se materializa de modo exemplar no prontuário do paciente); a obrigação de confrontar experiência e registro para avaliar tratamentos, êxitos, fracassos, etc ${ }^{(4)}$.

Nesse sentido, o hospital passou a funcionar não só como uma instituição de disciplinamento, controle e/ou cura de certos tipos de desordens reconhecidas e nomeadas como patológicas, mas, também, como uma instância de acúmulo, registro, produção e veiculação de um tipo específico de saber - a medicina clínica. O hospital transforma-se em lugar de formação privilegiada primeiramente de médicos e, crescentemente, de outros profissionais de saúde, como os da enfermagem moderna (que se organiza como profissão no século XIX). O saber clínico se estrutura e organiza o espaço, as relações e o fazer nesse contexto orientando-o para a intervenção sobre o corpo doente individual e funciona, ao mesmo tempo, como instância de produção de saber e, também, de formação profissional e de transmissão desse saber. Esse saber clínico que emerge se exercita, se amplia e subsidia vários outros tipos de saber, estabelece a partir daí como objeto de conhecimento um "imenso domínio, limitado de um lado pelo indivíduo e de outro, pela população", uma vez que o seu foco sobre o indivíduo, permite observar ao mesmo tempo uma grande quantidade de indivíduos e conhecer "fenômenos patológicos comuns a uma dada população"(4).

Eu estou pontuando estas coisas aparentemente desconexas e situadas em outro tempo histórico para tentar articular o argumento que propus inicialmente: uma discussão sobre algumas das dimensões da relação entre conhecimento e poder, no contexto de uma dada configuração hospitalar, pensando a posição do saber-fazer de enfermagem nesse contexto.

Com esse intuito, daquilo que escrevi sobre conhecimento científico quero lembrar as características que lhe são atribuídas dentro de uma certa perspectiva de ciência e a relação desse conhecimento com a produção do que conta verdade. Ressaltar, ainda, que a instituição e operacionalização de regimes de verdade centrados no discurso científico demandam a constituição concomitante de comunidades científicas no interior das quais se delimitam as condições de validação desse conhecimento

Do processo civilizador ${ }^{(3)}$ quero reter a idéia de que o que determina a complexidade de uma sociedade e, por conseguinte, de suas instituições, é a extensão das interdependências, o nível de divisão das funções e a estrutura interna das próprias funções, o que nos permitiria pensar que sociedades e instituições complexas se materializam sob a forma de redes das mais diversas. $E$ que, como integrantes de redes estamos - como indivíduos, grupos e instituições - sempre mergulhados em certos tipos de coletivos.

Da discussão sobre a emergência do hospital(4) quero reter a idéia de que o hospital se configura como um lócus onde produção de saber e intervenção sobre o corpo e a doença dos indivíduos estão intrinsecamente ligadas. $E$, ainda, que o processo de disciplinamento que tornou isto possivel demandou, ao mesmo tempo, tanto o privilegiamento de um profissional e de uma área do saber - a clinica médica e o médico - quanto o reconhecimento e a regulação das interdependências, a divisão das funções e o detalhamento cuidadoso das especificidades de cada uma das funções envolvidas nesses - e necessárias para esses - processos de conhecer e intervir.
Tomando estes pontos como referência, poderiamos, então, fazernos mais algumas perguntas: como a enfermagem tem participado e se posicionado nesse processo coletivo de produção de conhecimento científico sobre a doença e sobre o doente, nessa instituição social complexa que é o hospital? Como e onde seu saber-fazer se situa na cadeia cada vez mais extensa e especializada de interdependências e de divisão das funções que tornam essa instituição - e os conhecimentos que nela se produzem - possível? Como isso impacta e de-limita seu saber e seu fazer? Com que efeitos, para quem?

\section{ENFERMAGEM E PRODUÇÃO DE CONHECIMENTO. QUAL CONHECIMENTO? PARA QUE(M)?}

As perguntas acima enunciadas me colocam a necessidade de retomar, brevemente, algumas dimensões da emergência e consolidação da Enfermagem profissional moderna. As enfermeiras profissionais, desde o início, buscaram suporte em variados campos do conhecimento para apoiar o emprego de uma variedade de instrumentos e de procedimentos, no processo de avaliar, intervir e confortar seres humanos com problemas de saúde ou que estavam vivendo momentos particulares do seu ciclo vital (gestação, nascimento, primeira infância, velhice ou morte, etc). A Enfermagem profissional também foi definida, em seu início, como uma profissão feminina, cujo fazer estava centrado no cuidar, em oposição ao tratar que caracterizava a Medicina centrada no saber clínico, e que era representada como profissão masculina ${ }^{(5)}$.

Nesse processo de profissionalização da Enfermagem buscou-se, também desde o início, construir um campo de conhecimentos específicos que deveria tanto manter operantes os sistemas de valores que caracterizavam o feminino e o cuidado como sua extensão, quanto adquirir o estatuto de ciência. Nesse processo de cientifização de um saber até então qualificado como não científico o cuidar, em contraposição ao tratar, foi, grosso modo, tematizado de duas formas distintas e complementares: uma, onde a legitimação pela cientifização procurava conciliar a objetividade da ciência masculina com a intuitividade e a emoção que caracterizavam o feminino, posicionando o cuidado como interface de humanização na relação médico-paciente e, outra, muito atual, onde a ilimitada possibilidade de tecnologização de todas as dimensões do processo saúde-doença e as críticas ao paradigma de ciência que ainda sustenta, em grande parte, essa tecnologização, têm levado a uma teorização que, crescentemente, tematiza o cuidado como interface de humanização na relação médicotecnologia-paciente que aí se processa ${ }^{(6,7)}$. Tratar e cuidar, científico e não científico, masculino e feminino e, por extensão, Medicina e Enfermagem são, pois, oposições constitutivas dessa enfermagem que aprendemos e fazemos hoje. $E$ as teorias do cuidado, aqui genérica $e$ frouxamente enunciadas sem considerar a imensa gama de enfoques $e$ abordagens teóricas que têm sido utilizadas em sua enunciação, constituem o discurso científico em cuja produção e veiculação a enfermagem vem investindo na direção de disputar e dizer verdades sobre o corpo doente e a doença que segue se configurando como seu foco de atenção privilegiada, no âmbito do regime de verdade que institui e regula o saber-fazer em saúde que se materializa com, a partir e dentro da instituição hospitalar( ${ }^{(8)}$.

E ai meus argumentos se encontram com os de Araújo(9). Ao descrever e analisar, desde uma perspectiva foucaultiana, processos contemporâneos de subjetivação de enfermeiras, tomando como referência os registros das práticas assistenciais feitos pela enfermagem na UTI de um hospital escola, a autora levanta alguns pontos que, a meu ver, são fundamentais, para a reflexão sobre o saber-fazer de enfermagem, entendido como uma das dimensões constitutivas das redes, cada vez mais complexas, de produção de conhecimento em saúde.

Quero só relembrar, aqui, a centralidade atribuída ao sistema de 
registros no processo de medicalização do hospital e na constituição de um certo regime de verdade nesse território(4). E quero também lembrar que, na cadeia de interdependências e de divisão de funções que estrutura e dá ordem à complexidade da instituição hospitalar, cabe ao serviço de enfermagem (entendido aqui como um serviço regulado $e$ estruturado em relações para dentro - equipe de enfermagem - e para fora - equipe multiprofissional) uma parte substantiva desses registros. Considerando-se a permanência dessa equipe junto ao corpo doente, nas 24 horas do dia, durante sete dias da semana, poderíamos pensar que se espera, de forma idealizada, que ele funcione como um panóptico ${ }^{(10)}$ relativamente ao corpo doente e suas manifestações (observando, monitorando, encaminhando, intervindo e registrando, continuamente o que nele e em torno dele se passa).

$\mathrm{O}$ estudo antes mencionado ${ }^{(9)}$ considerou os registros hospitalares da enfermagem (em prontuários, relatórios, livros de ocorrência, encaminhamentos, passagens de plantão) como narrativas em que se podem analisar, concomitantemente, formas de objetivação do saberfazer enfermagem e formas de subjetivação do ser enfermeira ou membro da equipe de enfermagem. Vou pinçar duas ou três conclusões desse estudo que me parecem sumamente importantes para pensarmos o embate e a relação entre os discursos que disputam autoridade científica no contexto hospitalar.

A primeira grande conclusão do estudo é a de que o corpo apreendido e sobre o qual se age no contexto hospitalar segue sendo o corpo anátomo-clínico e que é este corpo que emerge, se mantém e se consolida, também, como o corpo do cuidado de enfermagem no hospital. As análises realizadas demonstram a competência da enfermeira no domínio da linguagem clínica e da semiótica e da semiotécnica que possibilitam a apreensão dos sinais e sintomas que a enfermagem registra, na ocupação dos espaços de intervenção que esse saber demarca, no reconhecimento das hierarquias e expertises que delimitam e conformam o processo coletivo de produção de conhecimento e de intervenção sobre a doença e sobre 0 doente, nessa complexa rede que configura a instituição hospitalar contemporânea.

As análises demonstram, também, que é o saber clínico que conforma e informa o saber-fazer, que se nomeia como sendo de enfermagem, nesse espaço e nessas relações. $E$ é isso que me interessa comentar aqui, na medida em que essa análise aponta para uma dissonância entre aquilo que se pretende que seja o objeto epistemológico da enfermagem - o cuidado em suas múltiplas acepções - e aquilo que se desenha como sendo o seu objeto de trabalho no cotidiano hospitalar ${ }^{(9)}$. Analisando os registros realizados pela enfermagem constata-se que seu foco substantivo são as práticas médicas e aquelas que se desdobram ou que dão suporte a ela: "as enfermeiras priorizam registrar certas práticas sobre o corpo: primeiramente e de forma muito detalhada práticas e intervenções médicas, seguidas de procedimentos técnicos em enfermagem"(9). Constata-se uma certa hierarquia nestes registros: "prioriza-se o registro da terapêutica médica, especialmente a medicamentosa, utilizando-se fundamentalmente a linguagem da clínica"(9). Nestes registros, aquilo que se denomina cuidado de enfermagem - ou seja, as intervenções de enfermagem sobre o corpo - estão fundamentadas no saber clínico e resultam de demandas colocadas pela terapêutica médica. Pouquíssimos registros evidenciam o cuidado como um saber/fazer específico e autônomo relativamente a este saber. Para além disso, e o que é mais importante, enquanto as práticas vinculadas ao exame, ao diagnóstico e à terapêutica médicas são extensivamente descritas e minuciosamente registradas, com delimitação de autoria e de expertise, os cuidados de enfermagem são prescritos e registrados de forma genérica ("feitos cuidados de enfermagem" ou, quando especificados, são apenas nomeados como procedimentos - "foi feito banho no leito"). Não se detalham tecnologias utilizadas para a efetivação do procedimento, não se registram reações do corpo a estes cuidados, não se nomeiam ou discriminam os agentes que 0 efetivam.

Considerando-se o volume dos registros elaborados pela enfermagem, o estudo constata que aquilo que supostamente constituí a especificidade desse campo - o cuidado - é muito pouco descrito e visibilizado. Desta forma, esse cuidado conforma-se como um cuidado prescritivo, que assume a forma de procedimentos técnicos apesar das tentativas de estabelecer "uma linguagem para o corpo, entendido como corpo do cuidado; de produzir uma metodologia para o cuidar chamada de metodologia da assistência de enfermagem; de instituir uma taxonomia diagnóstica de enfermagem"(9), dentre outras coisas que permeiam o processo de constituição de um campo do saber ancorado em Teorias do Cuidado. E ai, ao dizer que o hospital segue sendo o templo da clínica e que a UTI é o seu cenário exemplar, a autora argumenta que, mais do que qualquer outra função hospitalar, a enfermagem que ali se exercita funciona como "extensão do olhar e do braço médicos" $"(9)$.

Com essa afirmação, o estudo nos coloca, enquanto integrantes de uma comunidade envolvida com a produção de sistemas de validação de conhecimento, diante de algumas perguntas desafiadoras e instigantes: Existiria, no corpo, um domínio do cuidado? Como se realiza aquilo que denominamos de cuidado de enfermagem? 0 cuidado constitui mecanismos de visibilidade que nos permitem detalhar e descrever o corpo de formas específicas e colocá-lo como objeto de intervenções específicas e autônomas? ${ }^{\left({ }^{9}\right)}$ Ao que eu acrescentaria: $E$ dispomos de linguagens para isso? Que sistemas de validação de conhecimento essas teorias e as comunidades científicas que investem nelas têm produzido e legitimado?

\section{4. ...E POR QUE É PRECISO TERMINAR...}

De forma muito pontual, o estudo acima mencionado me faz retomar um enunciado recorrente nas discussões da área da enfermagem, sobretudo quando se pensam os processos de formação e sua relação com o exercício profissional: o da dicotomia entre teoria (o que se constrói como objeto epistemológico da enfermagem) e prática (o que se realiza como objeto de trabalho da enfermagem). Para Foucault e Deleuze ${ }^{(11)}$, a relação teoria-prática, tomada como resultado de pólos separados e unívocos de uma oposição binária, não se sustenta. Os autores trabalham com a noção de teoria como prática, enfatizando que não há teoria sem uma prática que a alimente, fortaleça e modifique e que não há prática sem uma teoria que a atravessa e lhe dá sustentação.

Tomadas dessa forma, teoria e prática são elementos distintos de um mesmo e indissociável movimento - 0 de conhecer os mundos em que vivemos e nos quais nos tornamos o que somos. Trata-se, então, de perceber que não estamos, aqui, diante de um fazer de enfermagem desvinculado de teoria, mas de um fazer de enfermagem produzido e orientado por outras teorias que não aquelas preconizadas, intencional e explicitamente, pela comunidade científica da área. Se voltarmos ao conceito de regime de verdade antes mencionado, podemos pensar que teoria e prática são também indissociáveis de formas de exercício de poder, porque buscamos conhecer, para controlar, potencializar e dominar a nós mesmos, aos outros e às coisas do mundo; e desenvolvemos formas de controle e de domínio, e instituímos campos de ação e de conduta por que estes nos permitem conhecer algo, conhecer de outras formas, conhecer outras coisas, num movimento incessante de continuidades e rupturas que fazem deste mundo um lugar tão interessante, prazeroso, disputado, e ao mesmo tempo, perigoso, de se viver.

Para finalizar, quero pontuar que 0 artigo pretendeu focalizar alguns limites e condições de possibilidade muito pontuais do saber-fazer de enfermagem, na complexa rede de saberes e fazeres que configuram a instituição hospitalar contemporânea. Saber-fazer esse que resulta de 
processos coletivos em um duplo sentido: coletivos porque resultam de embates dentro de um território que tem pretensões de se estabelecer como campo científico - a própria enfermagem; e coletivos, também, porque estes embates integram uma rede de saberes e funções interdependentes com os quais se disputam espaço e legitimidade - os saberes que integram a área da saúde, sob a égide do saber médico.

Tomando um elemento substantivo da prática da enfermagem no hospital como exemplo - os registros - coloquei para reflexão três perguntas inter-relacionadas e inter-dependentes: que saberes conformam e informam o fazer de enfermagem hospitalar? Que saberes o fazer de enfermagem, traduzido nos registros, reforça, legitima e retroalimenta? Como isso se dá e com que efeitos?

$\mathrm{E}$, ao priorizar estes desdobramentos do tema não pretendi defender ou apontar para a impossibilidade de um saber-fazer enfermagem centrado no cuidado. Ao contrário, ao encaminhar a discussão na direção de considerar que discursos e verdades científicas são "coisas deste mundo", feitas por seres deste mundo, pretendi apontar para o fato de que as coisas deste mundo podem ser questionadas e, portanto, também modificadas.

\section{REFERÊNCIAS}

1. Foucault M. Verdade e poder. In: Machado R, organizador. Microfísica do poder. $7^{\text {a }}$ ed. Rio de Janeiro (RJ): Ed. Graal; 1979. p. 1-14.

2. Costa DC, Costa NR. Teoria do conhecimento e epidemiologia: um convite à leitura de John Snow. In: Costa DC, organizador. Epidemiologia - teoria e objeto. São Paulo (SP): Hucitec-Abrasco; 1990. p. 167-202.

3. Elias N. O processo civilizador. Rio de Janeiro (RJ): Jorge Zahar Editora; 1993.

4. Foucault M. O nascimento do hospital. In: Machado R, organizador. Microfísica do poder. $7^{a}$ ed. Rio de Janeiro (RJ): Ed. Graal; 1979. p. 99-112.

5. Meyer DEE. Como conciliar humanização e tecnologia na formação de enfermeiras/os? Rev Bras Enferm 2002 mar-abr; 55(2): 189-95.

6. Rudge T. Situating wound management: technoscience, dressing and ‘other' skins. Nurs Inquiry 1999 sep; 6(3):167-77.
7. Fairman J, D'antonio P. Virtual power: gendering the nurse-technology relationship. Nurs Inquiry 1999 sep; 6(3):178-86.

8. Meyer D. Cuidado e diferença. Da integralidade à fragmentação do ser. Rev Gaucha Enferm 2001 jul; 22(2): 21-38.

9. Araújo LFS. Processos de subjetivação inscritos na constituição da experiência de si da/o enfermeira/o, nas práticas assistenciais de um cenário de trabalho exemplar - A Unidade de Terapia intensiva [tese]. Ribeirão Preto (SP): Escola de Enfermagem, Universidade de São Paulo; [s.d.].

10. Foucault M. Vigiar e punir. Nascimento da prisão. $9^{a}$ ed. Petrópolis (RJ): Vozes; 1991.

11. Foucault M, Deleuze G. Os intelectuais e o poder. In: Machado R, organizador. Microfísica do poder. $7^{\text {a }}$ ed. Rio de Janeiro (RJ): Ed. Graal; 1979. p. 69-78. 